Revista Educação e Políticas em Debate - v. 7, n. 3, p. 395-408, set./dez. 2018 - ISSN 2238-8346

\title{
O direito de ir, vir e interagir na educação superior: onde andam a acessibilidade e a inclusão?
}

The right to go, come and interact in higher education: where are accessibility and inclusion?

Le droit d'aller, de venir et d'interagir dans l'enseignement supérieur: où sont l'accessibilité et l'inclusion?

\author{
Maria do Carmo de Souza Batista ${ }^{1}$ \\ Universidade Federal do Piauí \\ Lázara Cristina da Silva ${ }^{2}$ \\ Universidade Federal de Uberlândia
}

Resumo: Quando se fala de acessibilidade e inclusão, há sempre um primeiro pensamento voltado para a deficiência física. Porém o atendimento à Pessoa com Deficiência $(\mathrm{PcD})$ ou mobilidade reduzida é apenas um dos vieses da acessibilidade, que abrange um contexto muito mais amplo, relacionado à todas as estratégias direcionadas à minimização das barreiras que impedem ou dificultam o acesso físico, tecnológico, comunicacional e atitudinal das pessoas que estão submetidos à alguma forma de deficiência. Este artigo objetiva revisar a literatura que trata da acessibilidade como política inclusiva na educação superior, com o intuito de contribuir para a disseminação das práticas efetivamente necessárias para o atendimento a esse público que, historicamente, é excluído e de valorizar um grupo social que necessita de apoio para a permanência e a conclusão dos estudos, abordando os pontos centrais ligados à responsabilidade social das Instituições de Educação Superior (IES) na adoção de estratégias e políticas educacionais em favor da inclusão.

Palavras-chave: Desconstrução de barreiras. Políticas de acessibilidade. Educação inclusiva. Educação Especial. Acessibilidade na educação superior.

Abstract: When it comes to accessibility and inclusion, there is always a first thought focused on physical disability. However, access to the Disabled (DPC) or reduced mobility is only one of the accessibility biases, which encompasses a much broader context, related to all strategies aimed at minimizing barriers that impede or hinder physical, technological, and communicational access and attitudinal of people who are subjected to some form of disability. This article aims to review the literature that delas with accessibility as na inclusive policy in higher education, with the purpose of contributing to the dissemination of the practices effectively needed to attend to this public who, historically, is excluded and to value a social group that needs support for the permanence and completion of the studies, addressing the central points linked to the social responsibility of Higher Education Institutions (HEI) in the adoption of educational policies in favor of inclusion.

Keywords: Deconstruction of barriers. Accessibility policies. Inclusive education. Special Education. Accessibility in higher education.

\footnotetext{
1 Doutoranda em Educação no Programa de Pós-Graduação em Educação PPGED (UFU). E-mail: mcbatista@ufpi.edu.br;

${ }^{2}$ Doutora em Educação. Professora da Faculdade de Educação na Universidade Federal de Uberlândia (UFU) Vinculada ao Programa de Pós-Graduação em Educação (PPGED/UFU).E-mail: lazara_cristina@hotmail.com.
} 
Résumé: Quand le fala de l'acessibilidade et de l'inclusion, há sempre um primeiro volamentado pour un deficiência física. Porem o atendimento à Pessoa com Deficiência $(\mathrm{PcD})$ ou mobilídá reduzida apenas um doses da acessibilidade, qui se trouve dans un contexte plus modeste, lié à toutes les stratégies visant à minimiser les obstacles qui entravent ou entravent l'accès physique, technologique, communicationnel et attitudinal des personnes qui sont sujettes à une forme de handicap. Cet article vise à passer en revue la littérature traitant de l'accessibilité comme une politique inclusive dans l'enseignement supérieur, dans le but de contribuer à la diffusion des pratiques effectivement nécessaires pour s'adresser à ce public historiquement exclu et valoriser un groupe social qui a besoin soutien à la permanence et à l'achèvement des études, en abordant les points centraux liés à la responsabilité sociale des établissements d'enseignement supérieur (HEI) dans l'adoption de stratégies et de politiques éducatives en faveur de l'inclusion.

Mots-clés: La déconstruction des barriers. Les politiques d'accessibilité. L'éducation inclusive. L'éducation spéciale. L'accessibilité dans. L'enseignement supérieur.

Recebido em: 09 de setembro de 2018 Aceito em: 18 de dezembro de 2018

\section{Introdução}

A temática da inclusão educacional vem sendo discutida e regulamentada no Brasil, com mais veemência, a partir da década de 1990. Tais regulamentações são resultado de muitas tensões e lutas políticas, em que as pessoas excluídas, consideradas minorias, dentre elas, as com deficiência, apresentaram suas demandas à sociedade, que historicamente as excluiu dos seus espaços participativos e produtivos. Essas reivindicações, após muitos embates políticos e sociais e avaliados os riscos e benefícios em favor do sistema político econômico, são aprovadas ou rechaçadas. Suas conquistas são processuais, mas representam um avanço para a categoria que passa a ser reconhecida por frações importantes da sociedade.

Esse reconhecimento no campo do direito das camadas excluídas, precisa ainda abrir espaços para sua valorização e potencialização enquanto grupo social que possui condições reais de inserção e vida social. Há necessidade de se possibilitar a visibilidade de suas potencialidades frente ao descrédito histórico que os anulou e inviabilizou, enquanto sujeitos com condições de vida social, econômica, política e cultural no País. Portanto, as mudanças ocorridas, inclusive na forma de se dirigir a este grupo da população, faz diferença na maneira como as situações cotidianas são conduzidas.

No caso de uma parcela dos excluídos, a que se refere à $\mathrm{PcD}$, destaca-se que o uso da palavra "deficiente", por focalizar a incapacidade à pessoa, entrou em desuso, mas o termo "deficiência”, por ser relativo à falta de acessibilidade nas condições de igualdade, continua em 
uso e se utiliza, normalmente, após os vocábulos pessoa ou estudante (CARVALHO, 2017); também, por ser tomada como um adjetivo, que denota apenas uma característica a mais de cada um que, embora importante, não a define enquanto pessoa. Para a $\mathrm{ONU}, \mathrm{PcD}$ é aquela que têm impedimentos de longo prazo de natureza física, mental, intelectual ou sensorial, os quais, em interação com diversas barreiras, podem obstruir sua participação plena e efetiva na sociedade em igualdades de condições com as demais pessoas (Convenção sobre os Direitos das Pessoas Com Deficiência, 2011).

Diante dessas modificações, preocupa-nos entender: como as Instituições de Educação Superior (IES) estão tratando as condições de acessibilidade para que, de fato, estes sujeitos ${ }^{3}$ possam ser inseridos nos diversos espaços da sociedade? Assim, considerando, que o direito à educação é um direto social inalienável de qualquer brasileiro, esse texto apresenta como proposta: refletir sobre o princípio da acessibilidade na educação superior, tomada como foco de formação pessoal e profissional de destaque na sociedade contemporânea. Não se restringe ao público da Educação Especial ${ }^{4}$, uma vez que a inclusão o abrange, mas não se reduz a ele, embora ofereça destaque a este público.

No caso de PcD, detaca-se a Lei 13.146 de 2015, Lei Brasileira de Inclusão da Pessoa com Deficiência, também definida como Estatuto da $\mathrm{PcD}$, foco legal quando se tratar deste público, tomado como referência para direcionamentos e reflexões propostos no texto, uma vez que esta objetiva a "assegurar e a promover, em condições de igualdade, o exercício dos direitos e das liberdades fundamentais por pessoa com deficiência, visando à sua inclusão social e cidadania” (BRASIL, 2015, p.1). Esta lei atualiza as discussões expressas em 1999 sobre a temática expressa pela a Lei no 7.853 .

\section{Acessibilidade e inclusão: aproximações terminológicas}

A inclusão educacional adentrou no Brasil com a aprovação da Constituição Cidadã, de 1988, fruto do processo de democratização do País, a qual garante direitos fundamentais para os cidadãos brasileiros. No texto constitucional são tomados como marcos definidores da inclusão educacional, o Artigo 205 que assegura o direito de todos à educação; o Artigo 206 que estabelece a igualdade de condições para o acesso e a permanência na escola; o artigo 208, Inciso V, que preconiza a garantia de acesso aos níveis mais elevados de ensino, pesquisa e criação artística,

\footnotetext{
${ }^{3}$ Neste texto entende-se por sujeito aquele que tem a função de agir sobre, determinar as ações e intervenções que irão ocorrer com autonomia, independência e emancipação. Um ser repleto de potenciais.

${ }^{4}$ Público da Educação Especial são as pessoas com deficiências (sensoriais, físicas e mentais), transtornos globais do desenvolvimento e altas habilidades/superdotação.
} 
segundo a capacidade de cada um. A partir de então, todo arcabouço legal do Pais passou a incorporar a educação inclusiva como princípio elementar.

A Lei 9394/96, Lei de Diretrizes e Bases da Educação Nacional (LDB), veio reforçar no campo educacional o expresso na constituição, regulamentando a educação nacional como um direito inalienável de todo cidadão brasileiro: educação inclusiva.

A inclusão, portanto, significa a organização e a implementação de ações educativas que facultem a apropriação do saber, do saber fazer e da capacidade crítica e reflexiva de todos; envolve a remoção de barreiras arquitetônicas, sobretudo as barreiras atitudinais, aquelas resultantes do olhar das pessoas "normais" 5 e desinformadas, para que se promova a adequação do espaço psicológico que será compartilhado por pessoas com muitas diferenças entre si (PEREIRA, 2107). Enfim, inclusão educacional enfoca a garantia do direito de todos à educação, independe de suas condições físicas, biológicas, mentais, econômicas, étnicas, etc.

Apesar dos avanços das últimas décadas, ainda existem diversas barreiras que se observam nas vias e espaços cotidianos. As principais barreiras são: (a) urbanísticas, presentes nas vias e nos espaços públicos e privados abertos ao público ou de uso coletivo; (b) arquitetônicas, existentes nos edifícios públicos e privados; (c) nos meios de transportes, coletivos e não coletivos; (d) nas comunicações e na informação, compreendidas como quaisquer entraves, obstáculos, atitudes ou comportamentos que dificultem ou impossibilitem a expressão ou o recebimento de mensagens e de informações por intermédio de sistemas de comunicação e de tecnologia da informação; (e) atitudinais, que são as atitudes ou os comportamentos que impeçam ou prejudiquem a participação social da $\mathrm{PcD}$ em igualdade de condições e oportunidades com as demais pessoas; (f) tecnológicas, aquelas que dificultam ou impedem o acesso da pessoa com deficiência às tecnologias; (g) instrumentais, presentes nos instrumentos, utensílios e ferramentas de estudo de trabalho e de lazer ou recreação; (h) programáticas, as barreiras invisíveis integradas em políticas públicas (leis, decretos, portarias) e normas ou regulamentos institucionais, empresariais, dentre outros (MENDONÇA, 2013; MARTINS et al., 2017).

Portanto, na ampla acepção do termo, a acessibilidade na educação representa um dos princípios da inclusão educacional, que implica em assegurar não só o acesso, mas condições plenas de participação e aprendizagem a todos os estudantes, com observância aos dispositivos legais, às orientações dos organismos internacionais e à política de democratização do ensino

\footnotetext{
${ }^{5}$ Neste caso, remete-se às pessoas sem deficiência, mas poderíamos também, fazer alusão às brancas, com poder aquisitivo médio a alto, com direitos civis e políticos assegurados historicamente.
} 
instituída pelo governo federal. Além do necessário "ir e vir”, é necessário o pleno "interagir e o incluir".

No tocante ao público da educação especial, outros dispositivos legais vêm sendo estabelecidos, a partir de então, com destaque para: (a) o Aviso Circular no 277/1996 que recomenda que as instituições possibilizem a flexibilização dos serviços educacionais, e da infraestrutura, assim como, promovam a capacitação de recursos humanos para possibilitar a permanência, com sucesso, dos estudantes nos seus cursos (BRASIL, 1996a); (b) o Decreto 3956/2001, que promulga a convenção interamericana para a eliminação de todas as formas de discriminação de PcD (BRASIL, 2001); (c) Lei 10.436/2002, que reconhece a Língua Brasileira de Sinais - Libras, como meio legal de comunicação e expressão, assim como outros recursos a ela associados, além da obrigatoriedade no ensino das Licenciaturas e de Fonoaudiologia (BRASIL, 2002a); (d) a Portaria $\mathrm{n}^{\circ}$ 2.678/2002, que trata da difusão do sistema Braille em todas as modalidades de ensino, no território nacional (BRASIL, 2002b); a Portaria 3284/2003, que dispõe sobre requisitos de acessibilidade de pessoas portadoras de deficiências, para instruir os processos de autorização e de reconhecimento de cursos, e de credenciamento de instituições (BRASIL, 2003); (e) a NBR 9054/2004 da ABNT, que dispõe sobrea acessibilidade a edificações, mobiliário, espaços e equipamentos urbanos (ABNT, 2004); (g) o Decreto 5296/2004, que regulamenta as Leis10.048/2000 e 10.098/2000 (BRASIL 2004a), estabelecendo critérios para ao atendimento prioritário a $\mathrm{PcD}$ em salas de aula, biblioteca, auditórios, ginásios, laboratórios, áreas de lazer e sanitários e recomendações legais diversas.

Para estes casos, a legislação mais atual é a Lei Federal nº 13.146/2015, que instituiu o Estatuto da Pessoa com Deficiência, o qual define acessibilidade (em seu art. $3^{\circ}$, inciso I) e a configura como a:

[...] possibilidade e condição de alcance para utilização, com segurança e autonomia, de espaços, mobiliários, equipamentos urbanos, edificações, transportes, informação e comunicação, inclusive seus sistemas e tecnologias, bem como de outros serviços e instalações abertos ao público, de uso público ou privados de uso coletivo, tanto na zona urbana como na rural, por pessoa com deficiência ou com mobilidade reduzida (BRASIL, 2015, p.1).

Acessibilidade representa, pois, a condição legal que objetiva a superação de qualquer tipo de barreira, sendo esta última caracterizada como o "entrave, obstáculo, atitude ou comportamento que limite ou impeça a participação social da pessoa, bem como o gozo, a fruição e o exercício de seus direitos à acessibilidade”, bem como a privação ao movimento, à 
liberdade de expressão, de comunicação e de acesso à informação, à captação do sentido ali expresso e à circulação com segurança (BRASIL, 2015, p. 1).

\section{Responsabilidade social das IES voltada para a acessibilidade e inclusão da PcD}

Entendida em seu amplo espectro, a acessibilidade pode ser: atitudinal, arquitetônica ou física, comunicacional, pedagógica, digital ou tecnológica, nos transportes e em todos os ambientes e pressupõe medidas que extrapolam a dimensão arquitetônica e abrangem o campo legal, curricular, das práticas avaliativas, metodológicas, entre outras (MOREJÓN, 2009; CIANTELLI, LEITE, MARTINS, 2016).

Na educação superior o debate sobre a inclusão se inscreve na discussão mais ampla do direito de todos à educação e na igualdade de oportunidades de acesso e permanência, com sucesso, nessa etapa de ensino. A inclusão e a acessibilidade inserem-se no rol dos atributos de responsabilidade social das instituições educacionais em todos os níveis, sobretudo no enfoque da valorização de sua missão pública, da promoção dos valores democráticos (SILVA; BARRETO, 2016).

A Lei 13.409/2016, que alterou a Lei 12.711/2012, a qual dispõe sobre o ingresso nas universidades federais e estabelecimentos federais de ensino técnico, determina que, nos processos seletivo para ingresso nos cursos de graduação, por curso e turno, no mínimo 50\% (cinquenta por cento) das vagas sejam ocupadas por autodeclarados pretos, pardos e indígenas e "por pessoas com deficiência, nos termos da legislação, em proporção ao total de vagas no mínimo igual à proporção respectiva de pretos, pardos, indígenas e $\mathrm{PcD}$ na população da unidade da Federação onde está instalada a instituição", segundo o último censo do IBGE (BRASIL, 2016). Assim, as IES precisam estar estruturadas de forma que esses alunos sejam efetivamente incluídos e encontrem as condições para a permanência enquanto concluem os seus cursos.

Os Referenciais de Acessibilidade na Educação Superior editados pelo INEP, consideram uma IES socialmente responsável, aquela que: (a) identifica as potencialidades e vulnerabilidades sociais, econômicas e culturais existentes na sua realidade local e global, para fins de promoção da inclusão plena; (b) traça metas e organiza estratégias para o enfrentamento e superação dessas fragilidades; (c) identifica a necessidade de mudança cultural e investe no desenvolvimento de ações de formação continuada para a inclusão, abrangendo os docentes e toda a comunidade acadêmica; (d) institui a acessibilidade plena a toda a comunidade 
interna (discentes, técnico-administrativos, docentes) e a externa que frequenta a IES ou que se beneficia de suas atividades e serviços (BRASIL, 2013).

No encadeamento das recomendações legais da educação inclusiva é possível perceber o aprofundamento da discussão sobre o direito de todos à educação, o que favorece a problematização acerca das práticas educacionais que resultam na desigualdade social de diversos grupos, do respeito à diferença e à diversidade humana (MIRANDA, 2014).

No contexto da responsabilidade expressa na função social, as IES, sejam federais ou privadas, se amparam, principalmente, em dois pilares: a Lei de Diretrizes e Bases da Educação Nacional (nº 9394/1996) e a Lei de instituição do Sistema Nacional de Avaliação da Educação Superior - Sinaes ( $n^{\circ}$ 10.861/2004), além da legislação específica editada pelo Estado Brasileiro (BRASIL, 1996; BRASIL, 2004).

O Decreto 7.611/2011, de 17.11.2011, que dispõe sobre a Educação Especial, o Atendimento Educacional Especializado (AEE) e dá outras providências, garante serviços de apoio especializado para a eliminação de barreiras que possam obstruir o processo de escolarização do Estudante com Deficiência $(\mathrm{EcD})$, Transtornos Globais do Desenvolvimento (TGD) e Altas Habilidades/Superdotação (AHS). O AEE compreende "o conjunto de atividades, recursos de acessibilidade e pedagógicos, organizados institucional e continuamente" para complementar a formação dos EcD, TGD e AHS ou suplementar a formação daqueles com AHS. Este Decreto estabelece também o apoio técnico e financeiro da União aos sistemas públicos de ensino dos Estados, Distrito Federal e Municípios e a instituições comunitárias, confessionais ou filantrópicas sem fins lucrativos para ampliar a oferta do AEE para o público alvo da educação Especial matriculado na rede regular de ensino (BRASIL, 2011; CIANTELLI, LEITE, MARTINS, 2016). O citado Decreto, ao se reportar à educação superior, no $\S 5^{\circ}$ do Artigo $5^{\circ}$, preconiza o apoio da União para implantação dos núcleos de acessibilidade, com vistas à eliminação das barreiras que restringem a participação e o desenvolvimento acadêmico dos EcD.

O Programa Incluir, instituído pelo MEC, por meio da Secretaria da Educação Continuada, Alfabetização, Diversidade e Inclusão - SECADI, em 2013, teve com o objetivo principal apoiar a criação e a reestruturação dos Núcleos de Acessibilidade e Inclusão (GONÇALVES, 2017) . Seu Documento Orientador trata a institucionalização da Política de Acessibilidade nas Instituições Federais de Educação Superior - IFES, a fim de assegurar o direito da $\mathrm{PcD}$ à educação superior, fundamentado nos princípios e diretrizes contidos na Convenção sobre os Direitos das Pessoas com Deficiência e nos Decretos n ${ }^{\circ}$ 186/2008, 
6.949/2009, 5.296/2004, 5.626/2005 e 7.611/2011, as IES precisam implementar núcleos de acessibilidade, estruturados com base nos seguintes eixos: (1) Infraestrutura - a concepção e a implementação dos projetos arquitetônicos e urbanísticos das IFES atendem aos princípios do desenho universal; (2) Currículo, comunicação e informação - disponibilização de materiais didáticos e pedagógicos acessíveis, de equipamentos de tecnologia assistiva e de serviços de guia-intérprete e de tradutores e intérpretes de Libras para garantir o pleno acesso, participação e aprendizagem; (3) programas de extensão - que assegurem a participação de toda a comunidade, por meio da efetivação dos requisitos de acessibilidade e disseminação de conceitos e práticas de acessibilidade por intermédio de diversas ações extensionistas; (4) programas de pesquisa - que propiciem o desenvolvimento de pesquisa básica e aplicada, abrangendo as inúmeras áreas do conhecimento, com fundamentação no princípio da transversalidade, do desenho universal e no reconhecimento e valorização da diferença humana (BRASIL, 2013).

É possível introduzir, dentro das especificidades de cada programa de pesquisa e de extensão, ações voltadas para articular, ressignificar e aprofundar aspectos conceituais e promover inovação, ao relacionar as áreas de pesquisa com a área da tecnologia assistiva, o que se configura em importante mecanismo para o avanço da inclusão social.

O Programa Incluir deixou de existir e as ações desenvolvidas pelas IES ligadas à temática pertinente ao $\mathrm{EcD}$, na maioria das IES foi encampada pelo Programa Nacional de Assistência Estudantil (PNAES), instituído em 2010, persistindo o compromisso institucional com a construção de uma sociedade inclusiva (GONÇALVES, 2017). O PNAES objetiva a democratizar as condições de permanência dos jovens na educação superior pública federal; minimizar os efeitos das desigualdades sociais e regionais na permanência e conclusão da educação superior; reduzir as taxas de retenção e evasão; e contribuir para a promoção da inclusão social pela educação (BRASIL, 2010).

\section{A obrigatoriedade das IES para com o cumprimento dos ditames legais}

É garantido à $\mathrm{PcD}$ pela $\mathrm{CF}-1988$, ratificado pelo Decreto 186, de 09.07.2008 e, mais recentemente pelo Decreto 7.611/2011, de 17.11.2011 e pela Lei Brasileira de Inclusão (no 13.146, de 06.07.2015): a proteção à vida, saúde, educação, moradia, trabalho e todo e qualquer direito inerente às demais pessoas. Assim, os compromissos institucionais das IES, sejam públicas ou privadas, para com a acessibilidade, como estratégia de inclusão, devem abranger: 
a) Plano de Desenvolvimento Institucional (PDI) que contemple as estratégias inclusivas, contemplando o apoio integral do $\mathrm{EcD}$, abrangendo a superação de todos os tipos de barreiras, já descritas anteriormente;

b) Projetos Pedagógicos Institucionais que descrevam, igualmente, as políticas inclusivas, em consonância com o PDI e com a Política Nacional de Educação Especial na Perspectiva da Educação Inclusiva (MEC, 2008). Devem incluir, em consonância com o PDI: (I) estratégias de ensino que possibilitem o envolvimento de todos, sem exceção; (II) cursos de extensão, exemplificados pelos de Libras e Braille para a comunidade e estudantes sem deficiência, objetivando que possam aprender e colaborar com o público usuário; (III) estratégias de iniciação científica que abordem essas temáticas;

c) Descrição, nos seus documentos legais, das condições de flexibilização dos serviços educacionais e da infraestrutura para possibilitar o acesso à educação superior, de conformidade com o 3298/1999 e o Aviso Circular 277/1996, do Gabinete do Ministério da Educação, que sugere o apoio institucional, pelo menos em três) momentos: (a) na elaboração do edital, para que possa expressar, com clareza, os recursos que poderão ser utilizados; (b) no momento dos exames, quando devem ser providenciadas salas especiais para cada tipo de deficiência e a forma adequada de obtenção de respostas pelo vestibulando; (c) no momento da correção das provas, quando será necessário considerar as diferenças específicas inerentes a cada $\mathrm{EcD}$, para que o domínio do conhecimento seja aferido por meio de critérios compatíveis com as características especiais desses alunos;

d) Reconhecimento da Língua Brasileira de Sinais (Libras) como meio legal de comunicação e expressão e outros recursos a ela associados, de conformidade com a Lei 10.436/2002 e a garantia do ensino de LIBRAS em todos os cursos de formação de professores e de fonoaudiologia, como disciplina obrigatória, e nos demais, como optativa, em atendimento ao Decreto 5626/2005. Ademais, deve haver tradutor e intérprete de Língua Brasileira de Sinais, guia intérprete, equipamentos de tecnologia assistiva e materiais pedagógicos acessíveis, atendendo às necessidades específicas dos estudantes;

e) Utilização do Sistema Braille, de conformidade com o documento da "Grafia Braille para a Língua Portuguesa, aprovado pela Portaria MEC 2678/2002, para fins de atendimento ao EcD no campo visual. Além disso, é necessária a utilização da tecnologia assistiva direcionada também aos estudantes com baixa visão como lupas, ampliadores de fonte e similares; 
f) A acessibilidade a edificações, mobiliário, espaços e equipamentos em geral, em observância à NBR 9050/2004, da ABNT, incluindo salas de aula, biblioteca, auditórios, ginásios, instalações desportivas, laboratórios, áreas de lazer e sanitários, segundo o Decreto 5296/2004. O cumprimento dessa norma de acessibilidade, neste caso, independe de haver matrícula de EcD na IES. Neste item se incluem as chamadas "adaptações razoáveis", que são as modificações e ajustes necessários e adequados, que não acarretam ônus desproporcional e indevido, mas que permitem ao EcD gozar de todos os direitos e liberdades fundamentais. De modo semelhante, o mobiliário pode ser adaptado (alargado, acoplado ou retirado uma peça para garantir a utilização pelo EcD. É obrigatória a colocação do Símbolo Internacional de Acesso (Lei $n^{\circ} 7405$, de 11.11.1985) em todas as edificações que ofereçam o acesso natural ou por meio de rampas e elevadores, bem como, disponibilização de bebedouros, telefones públicos e sanitários em altura compatível com a utilização pelo cadeirante, cujas especificações estão contidas nestas normas aqui citadas;

g) Planejamento e a implementação das metas de acessibilidade preconizadas pela legislação vigente, de responsabilidade do grupo gestão da educação superior, bem como, o monitoramento das matrículas dos $\mathrm{EcD}$ na instituição, para provimento das condições de pleno acesso e permanência;

h) Democratização das condições de permanência dos jovens na educação superior, garantindo condições que minimizem os efeitos das desigualdades sociais e regionais, apoiando, por meio de ações inclusivas os estudantes em situação de vulnerabilidade socioeconômica, de conformidade com o Decreto 7234/2010;

i) Transversalidade curricular das temáticas relativas aos direitos humanos, incluindo a dignidade humana, igualdade de direitos, o reconhecimento e a valorização das diferenças e diversidades, a laicidade do Estado, a democracia na educação, a transversalidade, do vivência e globalidade e a sustentabilidade sócio ambiental de conformidade com as Diretrizes Curriculares para a educação em Direitos Humanos, aprovadas pelo Parecer $\mathrm{CNE} / \mathrm{CP} \mathrm{n}^{\circ} 8 / 2012$.

No caso das instituições federais, por meio do programa Incluir, da SECADI-MEC, foi financiada a estruturação de Núcleos de Acessibilidade, os quais respondem pela organização de ações institucionais que garantam a integração de pessoas com deficiência à vida acadêmica, eliminando barreiras comportamentais, pedagógicas, arquitetônicas e de comunicação. Este Programa, no seu Documento Orientador explicita que a inclusão das pessoas com deficiência na educação superior deve assegurar-lhes, o direito à participação na comunidade, as 
“oportunidades de desenvolvimento pessoal, social e profissional, bem como não restringir sua participação em determinados ambientes e atividades com base na deficiência. Igualmente, a condição de deficiência não deve definir a área de seu interesse profissional”. Para que este direito de concretize, as IES deverão disponibilizar serviços e recursos de acessibilidade que assegurem plenamente a participação dos estudantes (MEC/SECADI, 2013, p. 11).

Enfim, a garantia de inclusão do $\mathrm{EcD}$, como direito ao acesso, à permanência e à terminalidade dos cursos de graduação, engloba: o desenho universal, as tecnologias assistivas, a eliminação de barreiras, as adaptações ambientais e de mobiliário, além de profissionais qualificados para o apoio. Vale dizer que o desenho universal não é simplesmente o desenho preconizado em lei, para designar um espaço adaptado, mas envolve o conjunto de artefatos ambientais, produtos e serviços que podem ser usados por pessoas de diferentes características antropométricas e sensoriais, de forma autônoma, segura e confortável, constituindo-se em elementos ou soluções que compõem a acessibilidade (GONÇALVES, 2017).

É importante ressaltar que existe uma variedade de sítios eletrônicos que possuem recursos de tecnologia assistiva que permitem o download gratuito, tanto em instituições públicas, como o da Câmara dos Deputados a SECADI, como várias ONGS e instituições privadas. Há as também bibliotecas virtuais que disponibilizam e-books, material em Braille e Libras e diversos outros recursos que favorecem o aprendizado do EcD.

\section{Considerações finais}

Incluem-se na temática da acessibilidade todas as estratégias que permitem o ir, vir e interagir de todas as pessoas, independente de sua condição física e social. Tratando-se especificamente da educação superior, as normas de acessibilidade são claras e a sua instituição é necessária tanto por parte da IES públicas, quanto das privadas. Adequações arquitetônicas, de mobiliário, documentais, comunicacionais, tecnológicas e, sobretudo, atitudinais, por meio da educação continuada, são importantes para que as pessoas, inclusive as $\mathrm{PcD}$, possam usufruir dos seus direitos fundamentais. Neste caso, a acessibilidade é um princípio da inclusão que embora tratado com reforço ao público da educação especial, ela também avança aos demais, pois torna possível o acesso às condições de escolarização, para todos, mesmo que para alguns a dificuldade esteja relacionada a uma condição e/ou tempo específico. Todos se beneficiam em uma sociedade inclusiva. 
Assim como cabe às IES a oferta das condições para que isso efetivamente ocorra, cabe à sociedade cobrar das IES o cumprimento das normas legais e, de modo, especial, é tarefa do EcD e de seus familiares, o processamento de requerimento contendo as condições necessárias para o atendimento específico de seus direitos.

Acessibilidade, democracia e direitos humanos são temas interligados, pois representam o direito e a valorização da diferença humana como instrumento de bem-estar e desenvolvimento inclusivo.

\section{Referências}

ABNT. Associação Brasileira de Normas Técnicas. NBR 9054/2004. Acessibilidade a edificações, mobiliário, espaços e equipamentos urbanos. 2004, 97 p. Disponivel em < http://www.pessoacom deficiencia.gov.br/app/sites/default/files/arquivos/\%5Bfield_generico_imagens-filefield-description \%5D_24.pdf>.Acesso em 03.jul.2018.

BRASIL. Constituição Federal de 1988. Disponível em: <http://www.planalto. gov.br/ccivil 03/ constituição /constituicaocompilado.htm>. Acesso em: 24 jun. 20158. Disponível em: <http://www. camara.gov.br/sileg/integras/566007.pdf>. Acesso em: 20 abr. 2018.

BRASIL. MEC. Gab.do Ministro. Aviso Circ. No 277/MEC/GM de 08.maio.1996. Disponível em <portal.mec.gov.br/seesp/arquivos/pdf/aviso 277.pdf. Acesso em 03.jul.2018. [BRASIL, 1996a].

BRASIL. Lei n. 9394 de 20 de dezembro de 1996. Estabelece as Diretrizes e Bases da Educação Nacional. Disponível em: <http://portal.mec.gov.br/arquivos/pdf/ldb.pdf>. Acesso em: 24 jun. 2015. [BRASIL, 1996b].

BRASIL. Lei n.10.098, de 19 de dezembro de 2000. Estabelece normas gerais e critérios básicos para a promoção da acessibilidade das pessoas portadoras de deficiência ou com mobilidade reduzida e dá outras providências. Disponível em <http://portal.mec.gov.br /arquivos/pdf/lei 10098.pdf>. Acesso em: 20 mar. 2017.

BRASIL. ${ }^{\circ}$ 3.956, de 08 de outubro de 2001. Promulga a Convenção Interamericana para a Eliminação de Todas as Formas de Discriminação contra as Pessoas Portadoras de Deficiência. Disponível emp://www. mpto. mp.br/ intranet/ caopdh/Outros /Conven \%C3\%A 7\%C3 \%A3o \%20Interamericana\%20para\%20a\%20Elimina\%C3\%A7\%C3\%A30\%\%20todas\%20as\%20Formas\%20d e\%20Discrimina\%C3\%A7\%C3\%A30\%20contra\%20as\%20Pessoas\%20.doc >.Acesso em 29.jun.2018.

BRASIL. MEC Portaria ${ }^{\circ}$ 2.678/2002, de 24 de setembro de 2002. Aprova o projeto da Grafia Braille para a Lingua Portuguesa e recomenda o seu uso em todo o território nacional. Disponível em $<\mathrm{http}$ ///www.fnde.gov.br/acesso-a-informacao/institucional/legislacao/item /3494-portaria-mecn\%C2\%BA-2678-de-24-de-setembro-de-2002>. Acesso em 04.jul.2018. [BRASIL,2002a]

BRASIL. Lei n ${ }^{\circ}$ 10.436, de 24 de abril de 2002. Dispõe sobre a Língua Brasileiraa de Sinais-LIBRAS e dá outras providências. Disponível em < https://pres.republica.jusbrasil.com.br/ legislacao/99492 /lei-de-libras-lei-10436-02> Acesso em 04.jul.2018. [BRASIL,2002b].

BRASIL. Portaria MEC 3284, de 07.11.2003. Dispõe sobre requisitos de acessibilidade de pessoas portadoras de deficiências, para instruir os processos de autorização e de reconhecimento de cursos, e 
de credenciamento de instituições. Disponível em http://portal.mec.gov.br/seesp/arquivos/pdf/ port3284.pdf >. Acesso em 04.jul.2018.

BRASIL Decreto $\mathrm{n}^{\circ} 5296$ de 02 de dezembro de 2004. Regulamenta as Leis $n^{\circ \mathrm{s}}$ 10.048, de 8 de novembro de 2000, que dá prioridade de atendimento às pessoas que especifica, e 10.098, de 19 de dezembro de 2000, que estabelece normas gerais e critérios básicos para a promoção da acessibilidade das pessoas portadoras de deficiência ou com mobilidade reduzida, e dá outras providências. Disponível em http://www.planalto .gov.br/ccivil_03/_ato2004 -2006/2004/ decreto/d5296.htm Acesso em 02.jul.2018. [BRASIL, 2004a].

BRASIL. MEC. Lei n ${ }^{\circ}$ 10.861, de 14 de abril de 2004. Institui o Sistema Nacional de Avaliação da Educação Superior - SINAES. Brasília, 2004. Disponível em: <http://www.inep.gov. br/download /superior/2004/ n10861_14_4_04>. Acesso em: 25.jan. 2015. [BRASIL, 2004b].

BRASIL. Decreto 6949, de 24 de agosto de 2009. Regulamenta a Lei $n^{\circ} 7.853$, de 24 de outubro de 1989 , dispõe sobre a Política Nacional para a Integração da Pessoa Portadora de Deficiência, consolida as normas de proteção, $e$ dá outras providências. Disponível em < http://www.planalto.gov.br/ccivil_03/decreto/d3298.htm>. Acesso em 18.jul.2018.

BRASIL. Decreto $\mathrm{n}^{\circ}$ 7.234, de 19 de julho de 2010. Dispõe sobre o Programa Nacional de Assistência Estudantil-PNAES. Brasília, 2010. Disponível em: <www.planalto/gov.br/civil_2010.htm>. Acesso em: 10.jan. 2014.

BRASIL. Decreto n ${ }^{\circ} 7.611 / 2011$. Dispõe sobre a educação especial, o atendimento educacional especializado $e$ dá outras providências. Disponível em <www.planalto.gov.br/ccivil_03/ato20112014/2011/decreto/d7611.htm>. Acesso em 18.jul.2018.

BRASIL. Lei n ${ }^{\circ}$ 13.146, DE 6 DE JULHO DE 2015. Institui a Lei Brasileira de Inclusão da Pessoa com Deficiência (Estatuto da Pessoa com Deficiência). Disponível em <http://www2. camara.leg. br/legin/fed/lei/2015/lei-13146-6-julho-2015-781174-publicacaooriginal-147468 -pl.html. Acesso em 18.jul.2018.

BRASIL, INEP. Referenciais de Acessibilidade na Educação Superior e a Avaliação In Loco do Sistema Nacional de Avaliação da Educação Superior (Sinaes). Parte I- Avaliação dos Cursos de Graduação. Brasília: INEP, julho de 2013, $51 \mathrm{p}$.

BRASIL. MEC. Documento Orientador Programa Incluir na educação superior-Secadi/Sesu- 2013, Brasília: MEC, 2013, 21 p.

BRASIL/MEC. Instituto Nacional de Estudos e Pesquisas Educacionais Anísio Teixeira Censo da Educação Superior. Resumo Técnico Censo da Educação Superior 2015. Brasília; INEP, 2018.

CARVALHO, Edneia Maria de Carvalho. Acessibilidade e inclusão de alunos com deficiência física e/ ou mobilidade reduzida: perspectivas de atuação da biblioteca escolar do Colégio Militar de Juiz de Fora. UNIRIO, 2017, 75 f. Dissertação (Mestrado em Biblioteconomia). Univ. Federal do Estado do Rio de Janeiro, Rio de janeiro, 2017.

CIANTELLI, Ana Paula Camilo; LEITE, Lucia Pereira; MARTINS, Sandra Eli Sartoreto de Oliviera. O Transtorno Global do Desenvolvimento na Educação Inclusiva: escola comum ou escola especial? Práxis Educacional, Vitória da Conquista, v. 10, n. 16, p. 105-127, jan/jun 2014,

GONÇALVES, Arlete Marinho. Núcleos de Acessibilidade: organização e funcionamento na atuação de pessoas público alvo da educação especial na educação superior. In: GONÇALVES, Arlete Marinho 
(Org.) Núcleos de Acessibilidade: práticas inclusivas com alunos com deficiência e transtornos funcionais específicos. Curitiba: CRV, Cap. 1: p. 13-32, 2017.

MARTINS, S. E. S. O.; GOMEZ, A. J. V.; FERNANDES, Y. Z.; BENETTI, C. S. Inclusão de universitários com deficiência na educação superior: o que dizem as pesquisas no Brasil e Uruguai. Jornal de Políticas Educacionais. v.11, n. 18, 27 de novembro de 2017.

MENDONÇA, Ana Abadia dos Santos. Escola Inclusiva: barreiras e desafios. VII Encontro de Pesquisa em Educação. Revista Encontro de Pesq. em Educação, Uberaba, v.1, n. 1, p. 4-16, 2013.

MIRANDA, Wagner Tadeu Sorace. Inclusão no Ensino Superior; das Políticas Públicas aos Programas de Atendimento e Apoio às Pessoas com Necessidades Educacionais Especiais. UNESP, 2014, 183 f. Tese (Doutorado em Educação) Universidade Estadual Paulista Júlio de Mesquita Filho, Marília, 2014.

MOREJÓN, KIzzy. O acesso e a acessibilidade de pessoas com deficiência no ensino superior público no Estado do Rio Grande do Sul. USP, 2009, 251 f. Tese (Doutorado em Ciências). Universidade de São Paulo, Ribeirão Preto, 2009.

PEREIRA, Josenilde Oliveira. Políticas Institucionais de Acessibilidade na Educação Superior: percursos e desafios para a inclusão de alunos com deficiência na UFMA. UFMA, 2017, 215 f. Dissertação (Mestrado em Educação). Universidade Federal do Maranhão. São Luís, 2017.

SILVA, Caroline B da A; BARRETO, Dagmar B. M. Estratégias de acessibilidade de alunos com deficiência no ensino superior: relatos de alunos com deficiência visual. Pesquisa em Psicologia. 2016.Anais Eletrônicos. Disponível em https://editora. unoesc.edu.br /index.php/pp _ae/article/ view/12004. 